\title{
Utilização de Realidade Aumentada e Virtual por Professores do Ensino Especial: uma análise de usabilidade e experiência do usuário
}

Franciane Lima, IFMA, frandeataide.fc@gmail.com, 0000-0002-1517-9213

Claudiene Sousa, IFMA, claudienesousa96@gmail.com, 0000-0003-2744-5547

Nicolas Melo, IFMA, nicolasoliveiramelo3@gmail.com, 0000-0003-4603-9480

Éville Ribeiro-Novaes, IFMA, eville.ribeiro@ifma.edu.br, 0000-0003-0906-8100

Davi Viana, UFMA, davi.viana@ufma.br, 0000-0003-0470-549X

Ariel Soares Teles, IFMA, ariel.teles@ ifma.edu.br, 0000-0002-0840-3870

Resumo: Este estudo objetivou identificar as percepções, em relação às tecnologias de Realidade Aumentada (RA) e Realidade Virtual (RV), como ferramentas educacionais, de professores da educação especial do ensino fundamental e médio de 8 escolas públicas de 2 municípios do Maranhão. Inicialmente, foi analisado o quanto professores têm conhecimento acerca da utilização de Objetos Digitais de Aprendizagem (ODAs) de RA e RV. Em seguida, ferramentas que podem ser utilizadas em aulas foram apresentadas aos participantes, visando avaliar a usabilidade e a experiência do usuário (UX). Os resultados mostraram que grande parte dos professores usam tecnologias digitais, mas não especificamente as de RA e RV. Os resultados também mostraram que as ferramentas propostas foram avaliadas positivamente em relação à usabilidade e UX.

Palavras-chave: Realidade Aumentada, Realidade Virtual, Necessidades Educacionais Específicas, Objetos Digitais de Aprendizagem, Usabilidade, Experiência do Usuário.

\section{Use of Augmented and Virtual Reality by Special Education Teachers: an analysis of usability and user experience}

Abstract: This study aimed to identify the perceptions, regarding the Augmented Reality (AR) and Virtual Reality (VR) technologies, as educational tools, of special education teachers in elementary and high schools from 8 public schools in 2 municipalities in Maranhão. Initially, it was analyzed how much teachers have knowledge about the use of Digital Learning Objects (DLOs) of AR and VR. Then, tools used in classes were presented to the participants, so aiming to assess usability and user experience (UX). The results showed that most teachers use digital technologies, but not specifically AR and VR. Results also showed that the proposed tools were positively evaluated in relation to usability and UX.

Keywords: Augmented Reality, Virtual Reality, Specific Educational Needs, Digital Learning Objects, Usability, User Experience.

\section{Introdução}

A evolução das tecnologias digitais vem acompanhada de inovações nos modos de comunicação e interação que podem se tornar úteis na construção do conhecimento. Este avanço tecnológico tem ainda proporcionado ferramentas que podem ser utilizadas para auxiliar no processo de ensino-aprendizagem. No contexto educacional, sabe-se que o ensino precisa se atualizar perante o avanço da tecnologia e da sociedade para que o espaço escolar consiga atender todos os alunos, independentemente de sua necessidade educacional, propondo um desafio aos professores para a obtenção de meios que inovem a prática pedagógica.

Os Objetos Digitais de Aprendizagem (ODAs) são recursos digitais que podem ser utilizados como suporte ao ensino visando a melhoria no processo de ensinar e aprender, oportunizando inovações pedagógicas. Visto que são materiais elaborados 
com objetivos educacionais, os ODAs têm como proposta facilitar a compreensão dos conteúdos. Em particular, os ODAs que usam as tecnologias de Realidade Virtual (RV) e Realidade Aumentada (RA) consideram o espaço tridimensional, permitindo uma experiência multissensorial aos seus usuários.

Segundo estimativas do Instituto Brasileiro de Geografia e Estatística (IBGE), os dados divulgados, a partir do censo de 2010, indicam haver mais de um milhão e meio de pessoas com algum tipo de deficiência no e stado d o Maranhão (BRASIL, 2010). Em relação ao quantitativo de estudantes com algum tipo de deficiência $m$ atriculados, de acordo com o Censo Escolar da Educação Básica (CEEB), realizado em 2019 do estado do Maranhão pelo Instituto Nacional de Estudos e Pesquisas Educacionais Anísio Teixeira (INEP), o número de matrículas da educação especial chegou a 44.029 (BRASIL, 2020) e teve um aumento de 43,9\% em relação a 2015.

É de fundamental importância que os recursos digitais disponíveis no espaço escolar não sejam apenas utilizados, mas também elaborados de modo a ajustá-los às necessidades educacionais dos alunos. Dessa forma, é preciso que os professores, como principais agentes da educação, adotem esforços para a compreensão sobre recursos e estratégias digitais, bem como sua aplicabilidade no âmbito educacional. Portanto, para que as tecnologias, tais como a de RA e RV, sejam usadas na prática docente, é primeiro necessário que os professores as aceitem como ferramenta educacional, incluindo de alunos com Necessidades Educacionais Específicas (NEEs).

Considerando esta problemática, este estudo objetivou identificar as percepções, em relação às tecnologias de RV e RA, como ferramentas educacionais, de professores de alunos com NEE do ensino fundamental e médio de 8 escolas públicas de 2 municípios do Maranhão. Inicialmente foi analisado o quanto professores têm conhecimento acerca da utilização de Objetos Digitais de Aprendizagem (ODAs) de RA e RV. Em seguida, ferramentas que podem ser utilizadas em aulas foram apresentadas aos participantes, visando avaliar a usabilidade e a experiência do usuário (User eXperience - UX).

O restante deste artigo está organizado como segue. A Seção 2 apresenta as concepções teóricas que norteiam e embasam a pesquisa. A Seção 3 descreve a metodologia adotada pelo estudo, enquanto a Seção 4 apresenta os resultados, e a Seção 5 os discute. Por fim, na Seção 6 estão as considerações finais.

\section{Fundamentação Teórica}

\subsection{Terminologias}

O termo utilizado para referenciar as pessoas que necessitam de políticas de inclusão, nos mais diversos campos da sociedade, passou por um processo de mudança. No que diz respeito ao campo da educação, observa-se a ocorrência de tentativas de se estabelecer terminologias corretas e de se possibilitar a utilização adequada, de modo a desencorajar práticas discriminatórias, principalmente quando se trata de assuntos relativos à deficiência.

$\mathrm{Na}$ história da educação especial no Brasil, verifica-se t ermos q ue j áforam utilizados para se referir aos educandos, como exemplo: débeis, retardados, incapacitados, inválidos, anormais, mongoloides (Lopes, 2014). Podem ser encontradas em diferentes documentos, dentre eles a primeira Lei de Diretrizes e Bases (LDB) de 1961 e a Constituição Federal, outras terminologias já utilizadas para se referir ao público-alvo da educação especial, tais como: portadores de deficiência, portadores de necessidades especiais, e excepcionais (Lopes, 2014).

A Convenção sobre os Direitos das Pessoas com Deficiência assinada pela Organização das Nações Unidas (ONU), afirma que: "pessoas com deficiência são aquelas 
que têm impedimentos de longo prazo de natureza física, mental, intelectual ou sensorial" (BRASIL, 2007). A designação "Necessidades Educacionais Específicas" é utilizada para se referir às pessoas que, para exercer os seus direitos educacionais, em igualdade de condições e oportunidades com as demais pessoas, necessitem de modificações e ajustes ao contexto escolar (Nascimento et al. 2015).

\subsection{O Atendimento Educacional Especializado}

A escola com orientação inclusiva requer uma transformação no sistema educacional que vai desde a gestão escolar, desenvolvimento profissional dos professores, até a adequação de condições físicas, materiais e ambientais que facilitem o ingresso de todos os alunos (Coll; Marchesi e Palacios, 2016). Além disso, é importante refletir também nas adaptações mais específicas de acordo com cada necessidade.

O Plano de Desenvolvimento da Educação (PDE) lançado em 2007, tinha como um de seus objetivos apoiar a organização da educação especial na perspectiva da educação inclusiva. Em 2011, foi lançado por meio do decreto $\mathrm{n}^{\mathrm{o}} 7.612$ o Plano Nacional dos Direitos da Pessoa com Deficiência - Viver sem Limite, tendo como objetivo "assegurar o pleno acesso dos estudantes da educação especial em igualdade de condições com os demais estudantes; disponibilizar recursos pedagógicos e de acessibilidade às escolas da rede pública de ensino; e promover o desenvolvimento profissional e a participação da comunidade escolar" (BRASIL, 2013).

Em relação à formação dos professores com atuação na educação especial, a Política Nacional de Educação Especial na Perspectiva da Educação Inclusiva (PNEEPEI) tem como objetivo "assegurar a formação de professores para o atendimento educacional especializado e demais profissionais da educação para a inclusão" (BRASIL, 2008). A inclusão social como fator fundamental para a igualdade requer que os educadores estejam informados sobre os processos educacionais e as possibilidades de integração, bem como o uso de ferramentas que facilitem o ensino.

O processo de inclusão tem como principal desafio a formação dos profissionais que atuam nos contextos escolares (Mendonça e Silva, 2015). As teorias transmitidas de forma mecânica, sem a devida articulação com as estratégias educacionais, são insuficientes para uma efetiva mudança nas concepções de ensino (Mendonça e Silva, 2015). A complexidade envolvida neste processo reforça a importância da formação dos professores, fator essencial para propiciar as mudanças exigidas pela educação inclusiva.

\subsection{Os ODAs de RA e RV no Processo de Ensino-aprendizagem}

Os ODAs são materiais elaborados com objetivos educacionais, utilizados como suporte ao ensino, incorporando tecnologias digitais de modo a facilitar o entendimento dos conteúdos pelos alunos (Schwarzelmüller e Ornellas, 2006). Alguns desses recursos tecnológicos possuem potenciais interativos e podem ser empregados em diversos ambientes, tais como a RV e RA.

A RV é uma técnica na qual o usuário realiza imersão (estar no ambiente), navegação e interação em um ambiente tridimensional (Ribeiro e Zorzal, 2011). Nesse ambiente, o usuário atua de forma multissensorial, explorando aspectos deste espaço por meio da visão e audição. De acordo com a tecnologia disponível, o paladar, o tato e o olfato também podem ser explorados (Kirner e Kirner, 2011).

A RA se constitui de técnicas computacionais que utilizam tecnologia multissensorial baseada em recursos multimídia e possibilita a criação de ambientes parcialmente artificiais, em que os usuários podem interagir com informações virtuais complementando o ambiente real (Araujo et al., 2017). A RA propicia ao usuário 
experiências que o levam a explorar o mundo real utilizando objetos virtuais, tais como: textos, imagens e vídeos.

No contexto educacional, a utilização de RV e RA está relacionada a seu emprego como ambiente de aprendizagem, por meio da possibilidade de imersão em ambientes virtuais ou mesmo pela criação de objetos virtuais que permitam complementar a percepção do mundo real. A utilização destas ferramentas pode favorecer a compreensão de conceitos considerados complexos. Por exemplo, no ensino de Ciências/Biologia, os conhecimentos envolvem conteúdos abstratos e muitas vezes de difícil compreensão, como o estudo da célula animal e vegetal, e suas estruturas, o organismo humano, e os mais variados eixos dentro desta disciplina. Estes conteúdos usualmente requerem uma exposição visual onde o aluno consiga absorver o assunto mais facilmente.

\section{Metodologia}

\subsection{Participantes}

Os participantes desta pesquisa foram recrutados em 8 escolas públicas dos municípios de Barreirinhas e Paulino Neves, no estado do Maranhão. Dois critérios de seleção foram considerados: (1) participantes que atuam, ou atuaram nos últimos 2 anos (2018 e 2019), diretamente com alunos com NEE; e (2) professores de Ciências/Biologia, dado que os ODAs propostos seriam relacionados a essas disciplinas. Um total de 17 professores atenderam os critérios, sendo 8 de Ciências (ensino fundamental II) e 9 de Biologia (ensino médio). Para ser realizada, esta pesquisa foi submetida ao Comitê de Ética em Pesquisa (CEP) através da Plataforma Brasil. Após estado de apreciação, ela foi aprovada sob parecer $\mathrm{n}^{\circ} 4.399 .156$.

\subsection{Procedimentos de Pesquisa}

Foram inicialmente definidas as escolas que iriam fazer parte deste estudo. Buscou-se um contato direto através de conversas com as direções das escolas para a autorização da pesquisa. O experimento realizado com os professores se deu em três etapas. Primeiramente, foi aplicado um questionário constituído de perguntas fechadas e de múltipla escolha. Ao iniciar o preenchimento dos questionários, os professores precisaram responder ao Termo de Consentimento Livre e Esclarecido para manifestarem sua concordância com a participação na pesquisa. Após o preenchimento do primeiro questionário, foi feito o uso dos ODAs propostos com a participação direta dos pesquisadores. Após o uso, houve a aplicação do segundo questionário com os professores para saber suas opiniões em relação aos ODAs utilizados.É importante ressaltar que os questionários foram aplicados de forma online com o auxílio da ferramenta Google Forms.

\subsection{Materiais}

Para a realização do experimento com os professores, os seguintes materiais foram utilizados: óculos 3D VR BOX e smartphones, para a visualização de ambientes imersivos dos ecossistemas locais em RV e de células animais, vegetais e bacterianas em RA. A construção dos ODAs de RV consistiu na criação de ambientes imersivos e interativos a partir de capturas de imagens panorâmicas em 360 graus. Para a obtenção das imagens utilizadas, foram visitados ecossistemas locais (i.e., rios e dunas - Figuras 1 e 2) dos municípios da pesquisa. As imagens foram feitas a partir de um smartphone com suporte para capturas em 360 graus.

Para a RA, foram utilizados aplicativos com leitura de $Q R$ Code, que serviram para identificar objetos presentes em imagens impressas. Dessa forma, utilizaram-se imagens sobre o assunto células, disponibilizadas pelos sites dos aplicativos. Os 


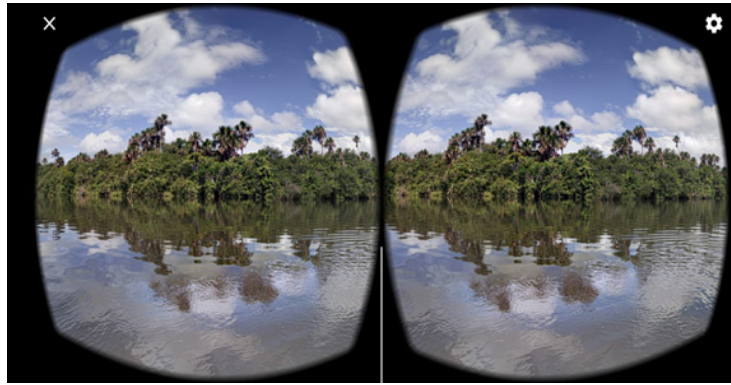

Figura 1. Rio Preguiças.

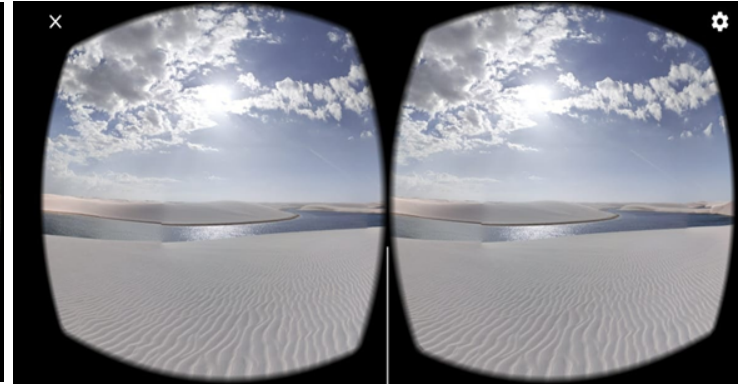

Figura 2. Lençóis Maranhenses.

aplicativos usados foram: División Mitótica $3 D$ e Ciência RA, disponíveis gratuitamente no Google Play.

\subsection{Coleta de dados e análise dos resultados}

O primeiro questionário continha perguntas destinadas aos professores, para conhecer suas concepções a respeito da utilização de ODAs, visando a inclusão de alunos com NEE. O segundo questionário continha o User Experience Questionnaire (UEQ), o qual é um instrumento utilizado para a avaliação da usabilidade e UX (Hinderks et al., 2019). O UEQ contém 26 itens em que os docentes responderam visando avaliar critérios de usabilidade e UX referentes aos ODAs de RV e RA. Os dados obtidos através dos questionários foram organizados sumarização através de gráficos e tabela.

\section{Resultados}

De acordo com o primeiro questionário sobre o conhecimento e experiência dos professores a respeito do uso de ODAs no ensino-aprendizado, quando perguntado se o docente já trabalhou ou trabalha com alunos que possuem NEE, $12(70,6 \%)$ professores responderam que já trabalharam anteriormente (nos últimos 2 anos), e 5 (29,4\%) disseram que atualmente trabalham. Aprofundando-se nesta informação, a Figura 3 apresenta a distribuição das respostas dos professores no que diz respeito às dificuldades que eles encontram, ou encontraram, no trabalho com os alunos com NEE. Vale ressaltar que esta questão era de múltipla escolha.

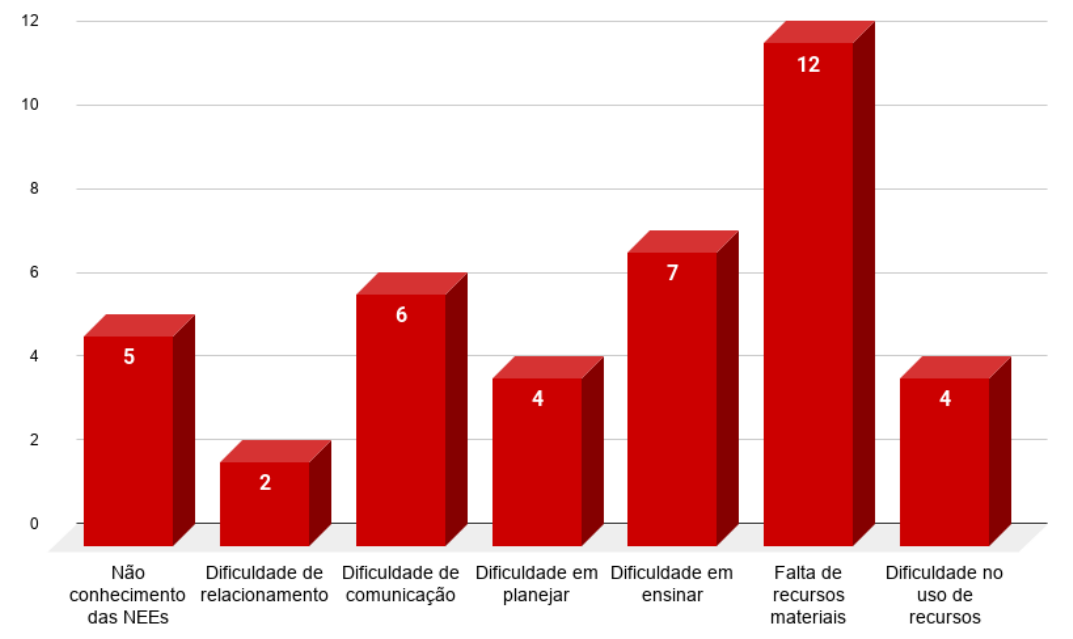

Figura 3. Dificuldades no trabalho com alunos com NEE. 
Ao analisar esse resultado, constata-se que a falta de recursos materiais pode ser um problema para os professores que precisam inovar. O professor pode fazer adaptações e ajustes nos objetivos pedagógicos de seu plano de trabalho para adequá-los às características e condições do aluno com NEE (Pimentel, 2012).

Quando questionado aos professores se há alguma orientação específica para o trabalho com os alunos com NEE na escola, a maioria dos docentes afirmou não haver orientação $(13,76,5 \%)$ e apenas 4 deles $(23,5 \%)$ responderam que sim. Dessa forma, percebe-se que as escolas necessitam capacitar seus professores para que os envolvidos no processo inclusivo possam desenvolver um trabalho adequado às necessidades dos alunos.

Sobre sua experiência a respeito das tecnologias digitais (Figura 4), a maioria dos professores $(n=16,94,1 \%)$ utiliza-as em sala de aula. Dentre os recursos tecnológicos mais utilizados, estão o projetor multimídia e o notebook. Dentre as outras opções menos/não utilizadas estão: soluções de software educacionais, plataformas virtuais, lousa digital, smartphone e tablet. Estas respostas demonstram o quanto se faz necessário que o professor utilize tais dispositivos, visando inovar em suas práticas educacionais.

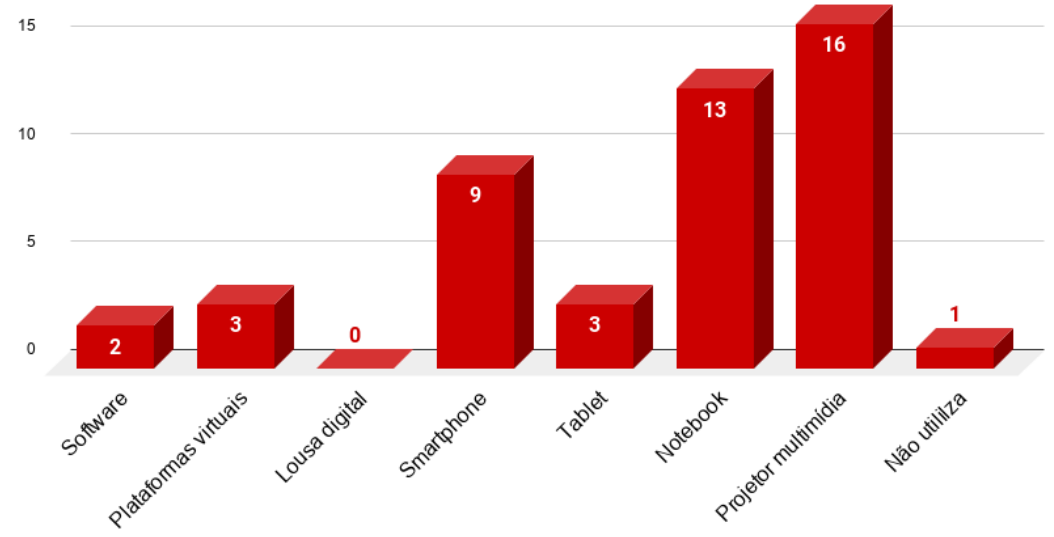

Figura 4. Recursos tecnológicos utilizados.

A Tabela 1 mostra a distribuição dos docentes em relação ao conhecimento das tecnologias de RA e RV. Sete $(41,2 \%)$ professores afirmaram conhecer a RA, e $8(41,1 \%)$ disseram conhecer a RV. A respeito do uso destas duas tecnologias digitais em sala de aula para o ensino de Ciências/Biologia de alunos com NEE, verificou-se que 2 docentes $(11,8 \%)$ já utilizaram como auxílio, e os outros $15(88,2 \%)$ nunca utilizaram. Dessa forma, pode-se observar as necessidades de conhecimento e utilização dessas ferramentas.

Tabela 1. Experiência dos docentes com RA e RV.

\begin{tabular}{|l|l|l|}
\hline Questão & Sim (\%) & Não (\%) \\
\hline \hline Você conhece a tecnologia de Realidade Aumentada (RA)? & 41,1 & 58,8 \\
\hline Você conhece a tecnologia de Realidade Virtual (RV)? & 47,1 & 52,9 \\
\hline $\begin{array}{l}\text { Você já utilizou as tecnologias de RV e RA no ensino de } \\
\text { Ciências ou Biologia para alunos com NEE? }\end{array}$ & 11,8 & 88,2 \\
\hline
\end{tabular}

Após o uso dos ODAs de RA e RV propostos, verificou-se no questionário pós-experimento UEQ as concepções dos professores em relação a estes ODAs. Na Figura 5, pode-se observar a representação da distribuição das respostas por itens individuais do UEQ. Percebe-se que os ODAs utilizados foram bem avaliados. Portanto, 
a usabilidade e UX por parte dos professores em relação às tecnologias digitais de RA e RV é considerada positiva, demonstrando viabilidade para uso em aula.

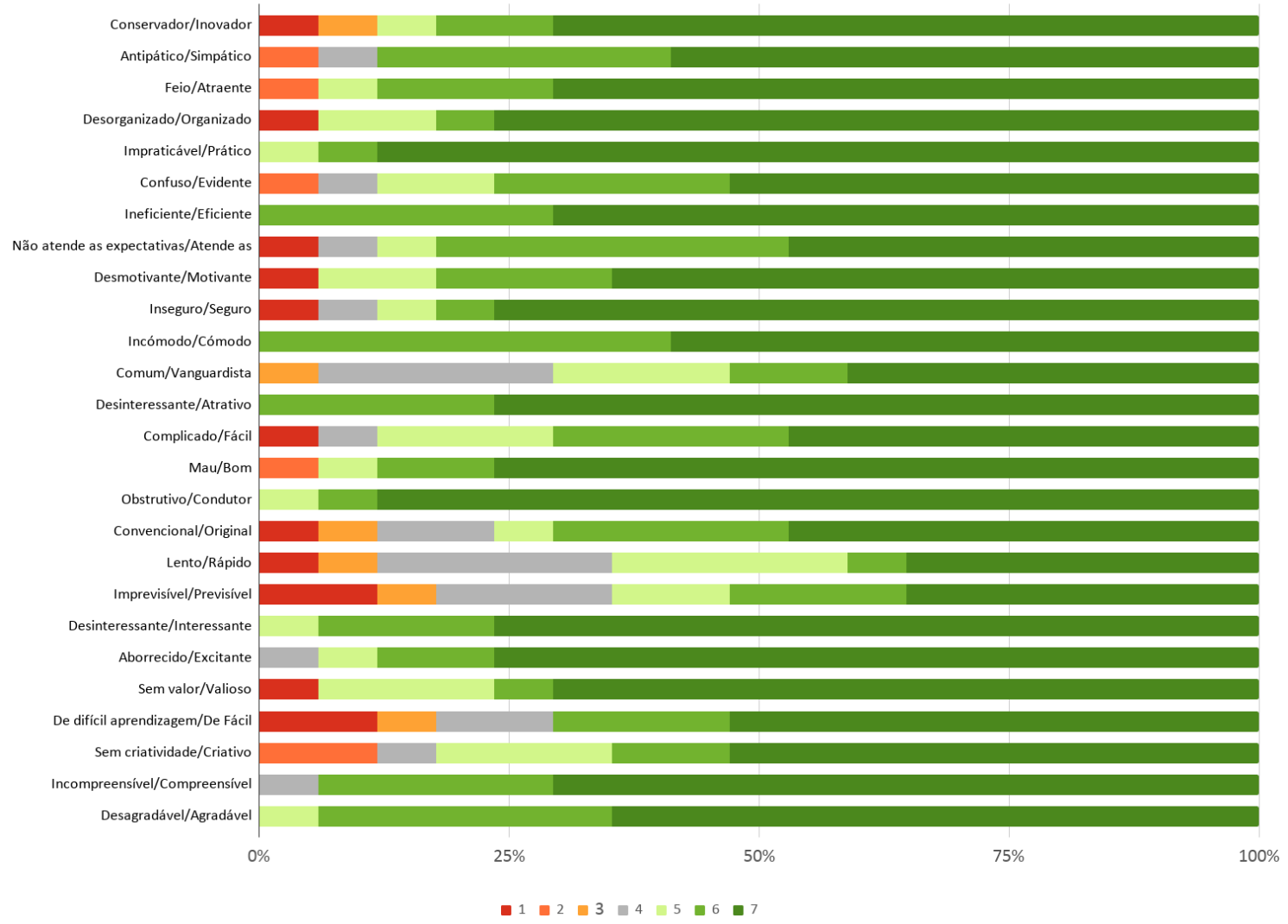

Figura 5. Distribuição das respostas por itens individuais.

O gráfico da Figura 6]apresenta a impressão dos docentes conforme aos 6 aspectos analisados pelo UEQ, os quais possuem resultados em uma escala de -3 a 3 . Observa-se que os resultados de todas as categorias se encontram na zona de pontuação positiva.

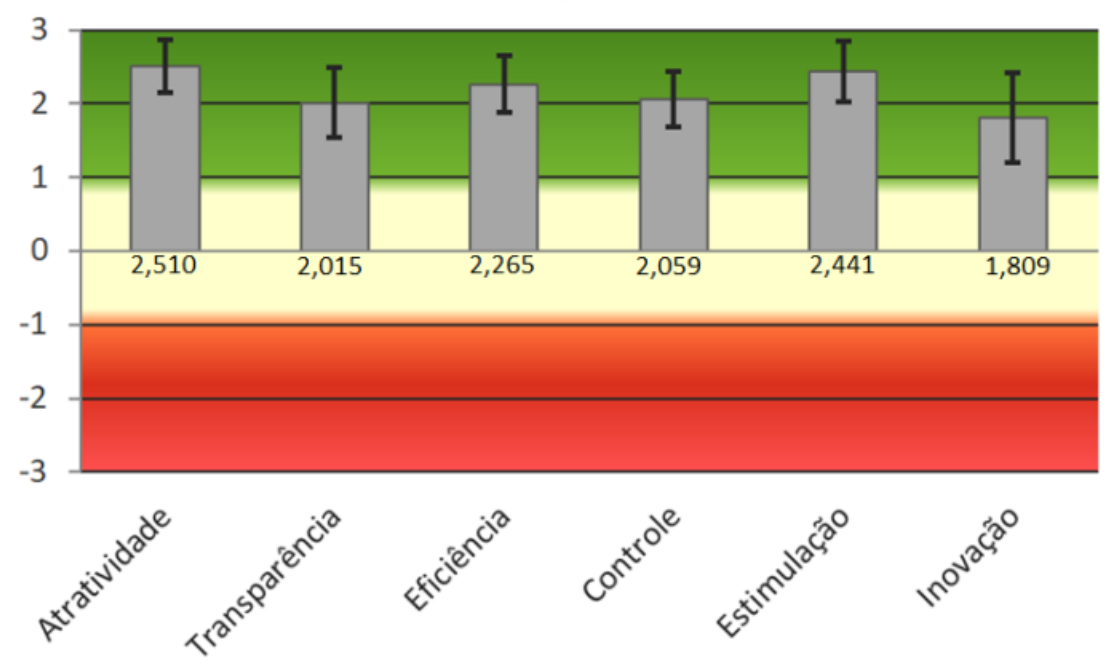

Figura 6. Impressão dos professores sobre uso dos ODAs conforme o UEQ.

As escalas do UEQ, divididas em seis aspectos, obtêm a impressão geral percebida de um produto (Hinderks et al., 2019). O aspecto atratividade significa que os usuários 
tiveram uma impressão ótima dos ODAs utilizados e acharam bastante agradáveis. $\mathrm{O}$ aspecto transparência significa q ue o s d ocentes c onsideraram o s O DAs f áceis e compreensíveis. Já o aspecto eficiência s e r efere à resolução de tarefas com facilidade e sem requerer esforço desnecessário. Controle significa que os ODAs utilizados foram de fácil manuseio, fazendo com que os usuários se sentissem no controle com a interação. Estimulação quer dizer que os usuários se sentiram motivados ao utilizar os ODAs. Por fim, o a specto i novação m ostra que o s d ocentes c onsideraram o s ODAs i novadores e criativos, e que prendem a atenção dos usuários.

\section{Discussão}

\subsection{Principais Achados}

A partir da análise dos dados, identificou-se que os professores participantes desta pesquisa fazem o uso de tecnologias digitais no ambiente escolar e que alguns apresentam conhecimento sobre a RA e RV. Porém, quanto ao uso desses ODAs como ferramenta didática para o ensino de Ciências/Biologia, os docentes mostraram pouca ou nenhuma experiência.

Os resultados do uso dos ODAs de RV e RA pelos professores foram percebidos de forma positiva, portanto mostrando viabilidade para uso em aulas, inclusive abrangendo alunos com NEE. Estes resultados inicialmente já faziam parte da hipótese deste estudo, visto que essas ferramentas podem ser inseridas na sala de aula possibilitando ao professor trabalhar com seus alunos as disciplinas de Ciências/Biologia, permitindo também a construção de novos ambientes de aprendizado dessas disciplinas. Além disso, o uso dessas ferramentas digitais, pela percepção dos professores, mostrou que elas podem despertar o interesse dos alunos, incluindo aqueles com NEE.

Segundo um mapeamento realizado em (Silva e Amaral, 2020), o processo educacional do aluno com NEE ainda evidencia um grande desafio p ara o s istema de ensino brasileiro, sobretudo na disciplina de ciências. Por isso, é importante a apropriação do ambiente educacional no campo das tecnologias digitais, a fim de utilizá-las de forma pedagógica. Acreditamos que quanto mais rápido a escola se familiarizar e conseguir usar esses meios de maneira adequada, mais assertiva será a implantação e uso das tecnologias digitais.

\subsection{Trabalhos Relacionados}

Outros estudos encontraram uma significativa r elação e ntre o u so d e ODAs de RV e RA e a melhoria do ensino. Os autores (Sousa et al., 2021) apresentaram um estudo envolvendo as tecnologias de RA e RV, no ensino de Ciências para alunos do AEE. Com a realização deste estudo, os autores afirmam que f oi p ossível vivenciar uma experiência promissora no que diz respeito ao ensino-aprendizagem na educação especial. As tecnologias de RA e RV, além de terem sido bem aceitas pelos alunos do AEE, auxiliaram na interação em sala de aula entre o educador e os educandos. Os autores em (Macedo e Góes, 2019) apresentaram uma sequência de atividades envolvendo um aplicativo de RA e material impresso interativo, utilizadas em uma série de aulas previamente planejadas. Este trabalho discutiu a integração da RA em dispositivos móveis no processo de ensino-aprendizagem e apresentou uma análise das contribuições dessa tecnologia em sala de aula. Os autores em (Lopes; Silva e Reis, 2018) propuseram um aplicativo que utiliza RV para auxiliar no ensino das letras do alfabeto e algarismos numéricos em Libras para deficientes a uditivos. Os pesquisadores constataram que os usuários demonstraram grande interesse no aplicativo para aprender Libras e que o uso da RV tornou o aprendizado mais divertido e envolvente. 
Diferente destes trabalhos, este estudo apresentou resultados de um experimento com a utilização de ODAs de RA e RV, buscando identificar o quanto professores de 8 escolas das cidades Barreirinhas e Paulino Neves tinham conhecimento acerca da utilização dessas tecnologias, além de verificar u sabilidade e U X p or p arte dos professores em relação a esses ODAs. Dessa forma, este estudo visou mostrar que essas ferramentas podem ser utilizados para facilitar o processo de ensino-aprendizado no contexto do estado do Maranhão.

\section{Conclusão}

Este estudo objetivou identificar o quanto os professores de Ciências/Biologia do ensino fundamental e médio de escolas públicas do Maranhão têm conhecimento acerca da utilização de ODAs de RA e RV visando a inclusão de alunos com NEE, e buscou verificar a usabilidade e UX por parte dos professores em relação a essas tecnologias. Os resultados mostraram que os professores possuíam um conhecimento prévio acerca das tecnologias digitais, pois já utilizavam no ambiente escolar. No entanto, com relação aos ODAs específicas de RA e RV, alguns docentes disseram ter conhecimento, mas a maioria possui pouca ou nenhuma experiência com essas ferramentas. Quanto à usabilidade e UX, após um processo de experimentação das ferramentas, os professores consideraram que os ODAs possuem viabilidade para uso no processo de ensino-aprendizagem de alunos com NEE.

A partir desse estudo, considera-se relevante a realização de novas pesquisas para entender o uso de ODAs de RA e RV para alunos com NEE. Em particular, trabalhos futuros visando identificar a a ceitação destas tecnologias por parte dos alunos são bem vindos. Além disso, estudos de longo prazo (ou seja, um semestre ou ano letivo) experimentando essas tecnologias seriam importantes para identificar a contribuição delas para a aquisição de conhecimento.

\section{Agradecimentos}

Os autores agradecem ao apoio do IFMA, FAPEMA e CNPq pelo apoio dado a este estudo. Eles também agradecem a participação voluntária das escolas e professores.

\section{Referências}

Araujo, L.; Xavier, E.; Vasconcelos, P.; Machado, M.; Tavares, T. Doctorbio: Um estudo de caso sobre a utilizaçao de recursos de realidade aumentada no ensino de ciências biológicas. In: Anais do Workshop de Informática na Escola. [S.1.: s.n.], 2017. v. 23, n. 1, p. 294.

BRASIL. Convenção sobre os Direitos das Pessoas com Deficiência. [ S.l.]: Brasília, 2007. Disponível em: 〈http://portal.mec.gov.br/index.php?option=com_docman\&view= download\&alias=424-cartilha-c \&category_slug=documentos-pdf\&Itemid=30192 $\rangle$.

Acesso em: 08 mar., 2021.

BRASIL. Política Nacional de Educação Especial na Perspectiva da Educação Inclusiva Brasília. [S.1.]: DF: Secretaria de Educação Especial, 2008. Disponível em: $\langle$ http://portal.mec.gov.br/arquivos/pdf/politicaeducespecial.pdf $\rangle$. Acesso em: 08 mar., 2021.

BRASIL. Instituto Brasileiro de Geografia e Estatística. Censo d o a no de 2010 do estado do Maranhão (MA). [S.1.]: Brasília, 2010. Disponível em: 〈https://censo2010. ibge.gov.br/sinopse/index.php?uf=21\&dados=26〉. Acesso em: 08 mar., 2021. 
BRASIL. Viver sem limite: plano nacional dos direitos da pessoa com deficiência. 2013. $\langle$ https://www.gov.br/mdh/pt-br/centrais-de-conteudo/pessoa-com-deficiencia/ cartilha-viver-sem-limite-plano-nacional-dos-direitos-da-pessoa-com-deficiencia

Acesso em: 08 mar., 2021.

BRASIL. Instituto Nacional de Estudos e Pesquisas Educacionais Anísio Teixeira. Resumo Técnico: Censo da Educação Básica Estadual 2019. [S.1.]: Brasília, 2020. Disponível em:〈http://portal.inep.gov.br/informacao-da-publicacao/-/ asset_publisher/6JYIsGMAMkW1/document/id/6874720〉. Acesso em: 08 mar., 2021. Coll, C.; Marchesi, Á.; Palacios, J. Desenvolvimento Psicológico e Educação-Vol. 3: Transtornos de Desenvolvimento e Necessidades Educativas Especiais. [S.1.]: Penso Editora, 2016. v. 3.

Hinderks, A.; Schrepp, M.; Mayo, F. J. D.; Escalona, M. J.; Thomaschewski, J. Developing a ux kpi based on the user experience questionnaire. Computer Standards \& Interfaces, Elsevier, v. 65, p. 38-44, 2019.

Kirner, C.; Kirner, T. G. Evolução e tendências da realidade virtual e da realidade aumentada. Realidade Virtual e Aumentada: Aplicações e Tendências. Cap, v. 1, p. 10-25, 2011.

Lopes, M.; Silva, L. R. da; Reis, D. Librar: aplicativo de aprendizagem de libras usando realidade aumentada e realidade virtual em dispositivo móvel. In: Anais dos Workshops do Congresso Brasileiro de Informática na Educação. [S.l.: s.n.], 2018. v. 7, n. 1, p. 946.

Lopes, S. A. Considerações sobre a terminologia alunos com necessidades educacionais especiais. Revista Educação Especial, v. 27, n. 50, p. 737-750, 2014.

Macedo, A. de C.; Góes, A. R. T. A integração da realidade aumentada em sala de aula: a pesquisa aplicada em colégios públicos do litoral paranaense. RENOTE, v. 17, n. 1, p. 1-10, 2019.

Mendonça, F. L. d. R.; Silva, D. N. H. A formação docente no contexto da inclusão: para uma nova metodologia. Cadernos de Pesquisa, SciELO Brasil, v. 45, n. 157, p. 508-526, 2015.

Nascimento, F. C. do; Martins, I. C.; Bugarim, M. C.; Martins, A. A ação tec nep-tecnologia, educação, cidadania e profissionalização para pessoas com necessidades específicas como ferramenta de inclusão nas instituições federais de educação profissional e tecnológica. InterSciencePlace, v. 1, n. 18, 2015.

Pimentel, S. C. Formação de professores para a inclusão: saberes necessários e percursos formativos. O professor e a educação inclusiva: formação, práticas e lugares. Salvador: EDUFBA, p. 139-155, 2012.

Ribeiro, M. W. S.; Zorzal, E. R. Realidade virtual e aumentada: Aplicações e tendências. XIII Simpósio de Realidade Virtual e Aumentada, Uberlândia-MG-Brasil, p. 15, 2011.

Schwarzelmüller, A. F.; Ornellas, B. Os objetos digitais e suas utilizações no processo de ensino-aprendizagem. In: Primeira Conferencia Latinoamericana de Objetos de Aprendizaje. [S.1.: s.n.], 2006.

Silva, R. S.; Amaral, C. L. C. A educação inclusiva no ensino de ciências e matemática: Um mapeamento na revista educação especial no período de 2000 a 2018. Communitas, v. 4, n. 7, p. 281-294, 2020.

Sousa, C. C.; Lima, F. de C.; Melo, N. O.; Novaes, E. K. D. R.; Teles, A. S. Realidades aumentada e virtual no ensino de ciências para alunos com necessidades educacionais específicas em uma escola pública de Barreirinhas-MA. Research, Society and Development, v. 10, n. 5, 2021. 